\title{
ARQUIVOS DE MUSEUS: CARACTERÍSTICAS E FUNÇÕES
}

\author{
Maria Celina Soares de Mello e Silva'
}

Museu de Astronomia e Ciências Afins/MAST/MCTI

\section{RESUMO:}

O artigo aborda as definições de arquivo e museu e a partir de seus objetivos, explora as características dos arquivos de museu apontadas pela literatura e traça as duas funções básicas do arquivo de museu, que são a de recolher e colecionar documentos.

\section{PALAVRAS-CHAVE:}

Arquivo de Museu. Coleção. Função do Arquivo. Arquivo Institucional. Características do Arquivo.

\begin{abstract}
:
The article discusses the definitions of archival and Museum and from your goals, explores the characteristics of the proposed literature Museum archives and traces the two basic functions of the Museum, which are to collect and collect documents.
\end{abstract}

\section{KEY-WORDS:}

Museum Archives. Collection. Archives Function. Institutional Archives. Archives Features. 


\section{Introdução}

As instituições arquivo e museu são antigas e hoje têm suas atribuições e características bem definidas e debatidas. Tanto os arquivos como os museus preservam acervos que são vistos como objetos de memória, processam informações e tornam disponíveis à sociedade. Mas também possuem os mesmos problemas, como pessoal qualificado e espaço físico, além de, como outras instituições culturais, estarem entre os primeiros a enfrentar as demissões e fechamento durante os períodos de escassez de recursos (WYTHE, 2004, p. 3).

Porém, quando se trata de um museu que possui um arquivo em sua estrutura, ou ao contrário, um arquivo que possui um museu, os arquivos passam a adquirir características, situação ainda pouco exploradas na bibliografia brasileira. O objetivo deste artigo é explorar o tema dos arquivos enquanto um serviço prestado por um museu, e as funções e características que este deve assumir por estar inserido no universo dos museus.

De início é preciso entender a definição de arquivo. $O$ arquivo tanto pode ser uma instituição como um todo, como, por exemplo, um arquivo municipal ou estadual; como também pode ser um setor em uma empresa ou instituição. Independente de seu status institucional, os objetivos de sua criação são os mesmos.Arquivo, segundo a Lei 8.159, de 8 de janeiro de 1991, que dispõe sobre a política nacional de arquivos públicos e privados e dá outras providências, é:

o conjunto de documentos recebidos e acumulados por órgãos públicos, instituições de caráter público e entidades privadas, em decorrência de exercício de atividades especificas, bem como por uma pessoa física, qualquer que seja o suporte da informação ou a natureza dos documentos (BRASIL, I99I).

Com este entendimento, a legislação brasileira chancela que os documentos oriundos da prática institucional ou de uma empresa, desde que produzidos no âmbito do exercício de suas funções e atividades, são considerados arquivo, qualquer que seja a instituição.

Já a definição de museu elaborada pelo Estatuto dos Museus, por meio da Lei II.904, diz que:

Consideram-se museus, para os efeitos desta Lei, as instituições sem fins lucrativos que conservam, investigam, comunicam, interpretam e expõem, para fins de preservação, estudo, pesquisa, educação, contemplação e turismo, conjuntos e coleções de valor histórico, artístico, científico, técnico ou de qualquer outra natureza cultural, abertas ao público, a serviço da sociedade e de seu desenvolvimento (BRASIL, 2009).

A definição apresentada pela lei é mais sucinta e objetiva. A definição elaborada pelo Instituto Brasileiro de Museus - IBRAM - especifica com mais detalhes, explicando as características dos museus²:

O museu é uma instituição com personalidade jurídica própria ou vinculada a outra instituição com personalidade jurídica, aberta ao público, a serviço da sociedade e de seu desenvolvimento e que apresenta as seguintes características:

I - o trabalho permanente com o patrimônio cultural, em suas diversas manifestações;

2 A definição de museu apresentada pelo IBRAM está disponível em:<http://www.museus.gov.br/museu/>. Acesso em: 06 mar. 2013. 
II - a presença de acervos e exposições colocados a serviço da sociedade com o objetivo de propiciar a ampliação do campo de possibilidades de construção identitária, a percepção crítica da realidade, a produção de conhecimentos e oportunidades de lazer;

III - a utilização do patrimônio cultural como recurso educacional, turístico e de inclusão social;

IV - a vocação para a comunicação, a exposição, a documentação, a investigação, a interpretação e a preservação de bens culturais em suas diversas manifestações;

V - a democratização do acesso, uso e produção de bens culturais para a promoção da dignidade da pessoa humana;

$\mathrm{VI}$ - a constituição de espaços democráticos e diversificados de relação e mediação cultural, sejam eles físicos ou virtuais.

Sendo assim, são considerados museus, independentemente de sua denominação, as instituições ou processos museológicos que apresentem as características acima indicadas e cumpram as funções museológicas.

O Conselho Internacional de Museus, em seu Código de Ética, ressalta que a missão de um museu é adquirir, valorizar e preservar suas coleções com a finalidade de salvaguarda do patrimônio natural, cultural e científico (INTERNATIONAL..., 2006).

Pode-se observar que tanto a definição de arquivo como a de museu contempla a autonomia enquanto instituição, ou admitem que possam ser vinculadas a outra entidade. E é justamente este último caso que os arquivos ou os museus se adaptam e acabam por assimilar as características um do outro.

Segundo Camargo,

Uma das características importantes do arquivo - e que é preciso levar sempre em consideração, é a de ser o resultado natural e necessário do funcionamento da entidade que lhe deu origem. Não se trata, pois, de uma coleção de documentos feita a partir de critérios seletivos e finalidades variáveis, como ocorre em bibliotecas e museus de perfil institucional especializado (CAMARGO, 20I0, p. 22).

O arquivo é o reflexo das atividades e da funcionalidade de uma instituição, pois é criado justamente para preservar os documentos que registram as atividades, servindo de testemunho e de prova das mesmas. Os documentos não são colecionados, eles são produto da instituição e são utilizados, em um primeiro momento, pela própria instituição, que necessita dos registros de sua trajetória por vários motivos, inclusive para a tomada de decisões, no âmbito administrativo. Em um segundo momento, os documentos passam a assumir um outro valor, diferente daquele que gerou sua produção, como, por exemplo, o valor histórico. É nesta fase que frequentemente pode ocorrer distorções de procedimentos. $O$ desmembramento de documentos de seu contexto original por serem considerados importantes para receber destaque fora do arquivo é mais comum do que se possa imaginar.

Camargo enfatiza a descaracterização dos documentos de arquivo e o próprio desmembramento do arquivo institucional, retirando alguns documentos do arquivo para compor centros de memória ou de documentação

Independentemente do uso que se faça deles no futuro, os documentos de arquivo continuarão a refletir as atividades de que se originaram 
- daí o imperativo de tratá-los de modo a garantir estabilidade a essa relação de correspondência (CAMARGO, 20I0, p. 24).

A manutenção da integridade do arquivo é importante, independente de ser uma instituição ou um setor de um museu. Os documentos devem ser preservados junto ao conjunto documental onde foi originado.

Como um organismo que reflete as atividades do museu ao qual pertence, o arquivo acaba por absorver algumas características do museu, conforme veremos a seguir.

\section{Características dos arquivos de museus}

As características dos arquivos de museus foram estudadas pelo Conselho Internacional de Arquivos, por meio da Seção de Arquivos de Museus. Os participantes dessa Seção produziram um livro com as diretrizes para a implantação de arquivos de museus (WYTHE, 2004), que enfatizam os pontos a serem observados:

I. Definição e escopo

2. Missão

3. Status do arquivo

4. Profissional arquivista

5. Documentação do museu e arquivos pessoais

6. Política de aquisição para coleta de materiais

7. Critérios de retenção dos documentos do museu

8. Arquivo corrente

9. Localização e condições

10. Arranjo, descrição e preservação.

II.Acesso

Para cada uma dessas diretrizes são fornecidas explicações sobre sua importância e significado. Mas estas são pertinentes também para qualquer tipo de arquivo, não apenas os de museus. Os autores enfatizam, porém, que o documento foi produzido para não arquivistas, apresentando as características básicas dos arquivos. $O$ documento pretende orientar a equipe do museu na implantação de um arquivo de museu.

Roberts considera que os arquivos de museus atuam como a memória do museu, assim como os arquivos de outras instituições (ROBERTS, [200-?]). Mas aponta que muitos arquivos de museus contêm pelo menos três tipos de documentos:

I. Documentos que são parte de sua coleção, incluindo itens como mapas, artefatos, fotografias e audiovisuais;

2. Material de arquivo pertencente a sua coleção, incluindo informação de proveniência;

3. Museus também gerenciam seu próprio arquivo institucional.

O primeiro refere-se ao documento do arquivo propriamente dito, ao seu acervo. $O$ segundo refere-se aos documentos que registram as peças do museu, que na museologia são os chamados registros do acervo. $\mathrm{E}$ o terceiro item refere-se aos documentos produzidos pelo museu no decorrer de suas atividades, ou seja, ao arquivo institucional. 
Para além dos documentos institucionais, a autora acrescenta que muitos arquivos de museus contêm itens que são coleções em e de si. Tanto arquivos pessoais quanto objetos pertencentes a personalidades ligadas ao museu podem ser encontrados nos arquivos.

Documentos de objetos, que registram a aquisição, catalogação, exposição, movimentação e conservação das coleções dos museus são considerados documentos típicos de missão; sem esses documentos, o museu não é capaz de funcionar. Como tal, eles são facilmente avaliados e devem ser mantidos. Uma vez que são continuamente ativos, no entanto, os documentos do objeto raramente são transferidos para os arquivos. Neste caso, a avaliação dever ser feita em cooperação com os membros da equipe que cuida desses documentos (WYTHE, 2004, p. 32, tradução nossa).

Trata-se de uma produção documental da instituição, que possui um uso corrente de longo prazo, permanecendo no setor onde foi produzido. O material produzido pelas exposições representa um volume considerável de documentos, que precisam ser avaliados. $O$ museu deve decidir quais poderão ser eliminados e quais serão encaminhados ao arquivo para a guarda permanente (WYTHE, 2004, p. 32). O mesmo ocorre com a pesquisa, que é uma atividade central em muitos museus. É preciso fazer a diferença entre o que pertence ao membro individual da equipe e o que é propriedade do museu. Os dados da pesquisa também podem permanecer de uso corrente por um longo prazo, pois os pesquisadores podem utilizá-los para diferentes pesquisas. Também podem ser compartilhados com pesquisadores de outras instituições.

As atividades e programas promovidos pelo museu, tais como programas educativos, eventos, visitas guiadas etc., também devem ter seus registros preservados no arquivo. São atividades com data marcada, com prazos de guarda nas fases corrente e intermediária fáceis de prever.

O sistema de gestão de documentos abrange todas estas atividades realizadas pelo museu. É importante que o plano de classificação de documentos, elaborado para o arquivo, contemple estas atividades e, ainda, que as equipes sejam treinadas para o arquivamento corrente e a classificação dos documentos ainda na fase corrente.

As características apontadas levam os arquivos de museus a desempenhar, assim, uma dupla função: recolher os documentos produzidos internamente pelo museu, e colecionar documentos de interesse do museu.

\section{Funções dos arquivos de museus}

Baseado na literatura, o que se pode perceber é que as características apontadas para os arquivos de instituições museológicas referem-se essencialmente a duas funções básicas dos arquivos de museus: recolher e colecionar. $A$ função de recolher refere-se à função de arquivo institucional do museu; e a função de colecionar refere-se à de preservar o acervo arquivístico adquirido pelo museu, de acordo com a política de aquisição institucional. Cada uma dessas funções possui características e procedimentos próprios, incluindo diferenças no processamento técnico das informações. Podemos resumir as duas funções como: recolher e colecionar. 
I) Função de arquivo institucional (recolher)

Os arquivos de museus exercem o papel de arquivo permanente (ou histórico) da instituição, recolhendo os documentos produzidos e acumulados pelo museu no exercício de suas atividades. Também deve ser da responsabilidade do arquivo a implementação e o gerenciamento de um programa de gestão de documentos, que regule a produção documental do museu.

Em geral, as instituições museológicas entendem o arquivo institucional como responsável pelos documentos produzidos pelas atividades administrativas ligadas às áreas-meio, não contemplando a documentação produzida pelas atividades das áreas finalísticas, como as de exposição ou pesquisa, por exemplo. Como consequência, documentos dessas atividades permanecem nos setores onde foram criados, ou mesmo podem ser descartados com o tempo. Por exemplo, a documentação de uma exposição, como projeto, plantas, cartas e convites, arte gráfica, relatório para os apoiadores, dentre outros, podem nunca chegar ao arquivo institucional. Essa documentação, oriunda das exposições que os museus promovem como atividades decorrentes da sua função social, leva a questionamentos sobre seu destino. Para Bevilacqua, que levanta a questão para os arquivos de museus de arte, este:

[...] material que não é documento de arquivo (pois não é constituído por registros documentais e processuais de atividades, mas pelo produto final em si de uma atividade), mas pode aparecer no arquivo (BEVILACQUA, 2010, p. I58).

O exemplo também é comum em outras tipologias de museus: o material das exposições nem sempre tem seu destino final determinado. Em alguns museus, os resquícios das exposições podem ir parar nos arquivos, mas, em outros casos, permanecem nos setores que produziu o material e seu destino é incerto: esquecimento ou descarte.

Desta forma, a documentação sobre as exposições deverão ser encaminhadas para o arquivo tão logo deixe de ser vigente.

Bevilacqua também defende que $o$ arquivo institucional de um museu tem como função manter atualizadas as informações sobre as exposições realizadas pelo museu (BEVILACQUA, 2010, p. I58). O material produzido pela atividade de realizar exposições em um museu é recolhido ao arquivo institucional. Nesse sentido, o autor explica essa função do arquivo institucional da Pinacoteca do Estado de São Paulo:

[...] Aqui vemos algumas atividades de pesquisa que o setor desenvolve. A primeira delas foi a complementação da cronologia histórica do museu, que virou uma atividade corriqueira. Hoje, uma das nossas funções é manter essa cronologia atualizada, juntamente com a lista de exposições realizadas pela Pinacoteca do Estado. No Cedoc ocorreu exatamente o que a Deborah Wythe colocou. Tradicionalmente, 0 primeiro trabalho de pesquisa se faz a partir do arquivo institucional organizado é o levantamento das exposições realizadas pelo museu (BEVILACQUA, 2010, p. 158-I59).

Um arquivo institucional organizado e atuante será capaz de fornecer informações sobre o histórico da instituição e, como ressalta Bevilacqua, "estranhamente, os museus são muitas vezes pouco preparados para dispor publica- 
mente de informações capazes de gerar reflexão sobre sua própria trajetória" (BEVILACQUA, 20I0, p. I6I).

O não encaminhamento de documentos para o arquivo institucional dispersa e dificulta a recuperação de informações para o próprio museu, para a recuperação de sua história, memória e feitos marcantes. Esta função de fornecer informações históricas sobre o museu é uma tarefa que deveria caber ao seu arquivo.

Os documentos produzidos pela atividade de documentar as coleções podem causar problemas terminológicos. Em geral, na área de arquivo, a documentação refere-se ao conjunto de documentos de um arquivo, ou seja, ao próprio acervo. Na museologia, a documentação refere-se aos documentos produzidos pela atividade de pesquisa, que identifica e contextualiza as peças e coleções do acervo de um museu. Nesse sentido, essa documentação permanece sob a guarda da equipe de tratamento museológico por um prazo longo, senão indeterminado. Para a arquivologia, poderia se dizer que esses serão utilizados por um longo prazo no arquivo corrente, já que são de uso contínuo pela equipe que o produziu.Assim, os prazos de guarda da documentação sobre a coleção deverão ser avaliados pelo arquivo e definidos em conjunto com os museólogos.

O arquivo de museu deve realizar um levantamento da produção documental de todas as atividades da instituição, área meio e fim, e estabelecer os prazos de guarda nos setores, bem como os prazos de encaminhamento para o arquivo institucional ou eliminação. É preciso que os museus entendam o programa de gestão, características dos programas de arquivo, em suas fases correntes - quando os documentos ainda estão sendo utilizados pelos setores que os produziram - na intermediária, quando os documentos não são mais de uso corrente, mas podem ser auditados ou consultados sem frequência; e a permanente - quando então os documentos são recolhidos ao arquivo institucional para guarda e uso.

\section{2) Função de aquisição de acervos arquivísticos (colecionar)}

Os arquivos de museus têm a missão de atuar no planejamento da política de aquisição de documentos arquivísticos por parte da instituição, em conformidade com a de acervos museológicos. Os museus, em geral, praticam uma constante busca de novos itens que complementem sua coleção, seja por compra, doação, permuta ou comodato. Os itens adquiridos para integrar o acervo do museu podem possuir características de documentos bibliográfico, museológico ou arquivístico.

Esses documentos podem apresentar os mais variados gêneros (textual, iconográfico, cartográfico etc.) e suportes (papel, madeira, metal, magnético, eletrônico etc.). Os documentos arquivísticos adquiridos devem ficar sob a guarda do arquivo. Esta recomendação refere-se tanto para a aquisição integral de um fundo, como para documentos avulsos, separados de seu contexto de produção. Mesmo considerado como peça única, isolada, o item documental deve ser tratado arquivisticamente.

Sem a intenção de entrar na discussão terminológica entre "prova documental”,"artefato" e "objeto", cuja distinção é difícil de determinar, arquivos institucionais com frequência contêm placas comemorativas, bótons, galhardetes, selos ornamentais, troféus, bustos e outros objetos tridimensionais produzidos, recebidos ou adquiridos pela instituição (WYTHE, 2004, p. 3).

A aquisição de documentos arquivísticos pelo museu deve ser regulada por uma política de aquisição, tal como para o acervo museológico. A política 
deve contemplar os objetivos e a missão do museu, e prever os temas, os tipos de acervo e diversos critérios de seleção, a serem estabelecidos pela instituição. Além disso, e igualmente importante, é a definição das responsabilidades sobre o acervo. Se o museu possui um arquivo, o acervo arquivístico adquirido deve ficar sob sua guarda, bem como o acervo bibliográfico deve ficar sob a guarda da biblioteca. Se não fisicamente, pelo menos por meio do controle intelectual.

Em geral, o acervo arquivístico adquirido pelo museu trata-se de arquivos oriundos de pessoas e entidades privadas, na forma de arquivos e coleções pessoais, cujo conteúdo é compatível ao interesse dos objetivos da instituição, tanto pela temática, quanto pela relevância da atividade do produtor do arquivo. A complementação de temas e de coleções museológicas é um forte argumento nas políticas de aquisição de acervos.

A atividade de pesquisa para coleta de informações é fundamental até para a própria atividade de organização do arquivo. Para Bevilacqua,

É fundamental deixar claro que nenhuma atividade de coleta de informações e documentos não arquivísticos é necessariamente inadequada no âmbito das funções do arquivo, mas sim que ela deve ser bem delimitada e estar organizada de acordo com as demais prioridades existentes no setor (BEVILACQUA, 2010, p. 157).

A política de aquisição deve regular a entrada de documentos arquivísticos ou coleções de documentos, prevendo a área de interesse, a identificação da proveniência, as datas ou período pertinente, além da responsabilidade interna pela guarda e preservação física dos mesmos. A política é um instrumento fundamental para a profissionalização das atividades, determinando os procedimentos, delimitando ações e traçando limites. A política de aquisição dá respaldo e transparência ao processo decisório.

No caso de museus que adquirem arquivos pessoais, estes podem vir acompanhados de artefatos e objetos em geral. A aquisição desse material é pertinente e deve estar contemplada na política de aquisição. Normalmente, arquivistas não recebem objetos em arquivos e a questão é controversa na literatura. Alguns arquivistas consideram que os objetos podem ter sido produzidos ou adquiridos no âmbito do desenvolvimento de uma atividade, institucional ou pessoal, e que, portanto, podem ser considerados documentos de arquivo. $O$ importante é que, antes da aquisição, o objeto ou artefato deve ser avaliado pela equipe responsável pelo acervo museológico e seguir os mesmos critérios de análise utilizados para o acervo museológico, tais como procedência, tipologia e estado de conservação, dentre outros (SILVA, 20I2).

A interação entre $o$ trabalho da equipe de museologia e da equipe do arquivo é fundamental para a contextualização do acervo. Mesmo que objetos sejam adquiridos pelo arquivo, seu processamento e preservação devem ser da responsabilidade da equipe de museologia, capacitada para lidar com este material. Ressalta-se, porém, que a proveniência nunca seja perdida, e esteja registrada nos instrumentos de pesquisa. Tal situação será possível pela integração entre os trabalhos das equipes e pelo amadurecimento institucional sobre os aspectos que envolvem a preservação de acervos.

\section{O papel do arquivista do museu}

$O$ arquivista que exerce suas atividades em museus tem como funções, além das tradicionais de avaliar os documentos institucionais de valor perma- 
nente e fornecer diretrizes para o recolhimento de documentos, as de servir como uma fonte de informação sobre a história do museu. Assim, segundo Morris (2003), o arquivista acaba por exercer funções de historiador, curador de coleções especiais e gestor de documentos. Para o autor, as funções dos arquivistas de museus seguem sendo: avaliar, arranjar, descrever e tornar acessíveis documentos de valor permanente. Para tal, precisa proteger e acondicionar documentos institucionais, organizá-los de acordo com as normativas arquivísticas, criar instrumentos para o acesso, fornecer serviços de referência à equipe e ao público, bem como conduzir trabalhos de história oral. $\mathrm{O}$ arquivista de museu busca, ainda, identificar todos os documentos do museu e determinar quais são correntes e quais irão para o arquivo, e preservá-los para o uso futuro.

O arquivista do museu não deve atuar sozinho, sem o apoio de outros profissionais. Flecker (1990) lamentou que muitos arquivistas e museólogos trabalhem na mesma instituição quase que isolados um do outro, tendo sua própria literatura profissional, suporte institucional e metodologia, mesmo que para tocar funções similares. Um dos resultados deste longo tempo de não relacionamento tem sido que - até relativamente recente - profissionais de museus, embora colecionadores ávidos por natureza e necessidade, geralmente não reconhecem a importância de documentar suas próprias atividades, coletando, mantendo e tornando acessíveis os documentos de suas instituições (MORRIS, 2003, p. 3).

Uma responsabilidade básica para os arquivistas e museólogos é o desenvolvimento e implementação de normas para as práticas profissionais de ambos, onde são definidos limites, competências e responsabilidades mútuas. A interação de ambos permitirá que um aprenda com o outro (FLECKER, 1990, p. 69).

\section{Arquivo versus Coleção}

Uma questão importante de se abordar é a diferença entre arquivo e coleção, ou entre fundo e coleção. Museus adquirem seus acervos que comumente são chamados de coleções. $E$ isto tem sido aplicado inclusive para os acervos arquivísticos. A identificação de um acervo como arquivo ou coleção muitas vezes é equivocada.

O ICOM, em seu código de Deontologia, alerta para a diferença entre coleção e fundo, o que se torna realmente necessário, já que museólogos não costumam lidar com esta questão em seu ofício:

Para constituir una verdadera colección es necesario que el agrupamiento de objetos forme un conjunto relativamente coherente $y$ significativo. Es importante no confundir colección con fondos. Estos últimos designan un acervo de documentos de todo tipo 'reunidos automáticamente, creados y/o acumulados y utilizados por una persona física o por una familia en el ejercicio de sus actividades o de sus funciones' (Oficina Canadiense de Archivistas, 1992). En el caso de los fondos, contrariamente a una colección, no hay selección y pocas veces la intención de constituir un conjunto coherente. Ya sea material o inmaterial, la colección figura en el corazón de las actividades del museo.'La misión de un museo es adquirir, valorizar y preservar sus colecciones con el fin de contribuir a la salvaguarda del patrimonio natural, cultural y científico' (INTERNATIONAL..., 2006).

Tessitore também alerta para esta questão, quando trata de sua experiência na organização do arquivo permanente do Museu Paulista. A autora per- 
cebeu que os dois equívocos no que diz respeito a arquivos de museus são:"a confusão da coleção como parte do arquivo e o tratamento do próprio arquivo como coleção do museu como sendo seu arquivo" (TESSITORE apud BEVILACQUA, 20I0, p. 16I).

Para dirimir tais enganos, precisamos entender o conceito de coleção e fundo. Na versão espanhola dos "Conceitos chave" da Museologia, produzido pelo ICOM, coleção está explicada como:

De manera general, una colección se puede definir como un conjunto de objetos materiales e inmateriales (obras, artefactos, mentefactos, especimenes, documentos, archivos, testimonios, etc.) que un individuo o un establecimiento, estatal o privado, se han ocupado de reunir, clasificar, seleccionar y conservar en un contexto de seguridad para comunicarlo, por lo general, a un público más o menos amplio (DESVALLÉES; MAIRESSE, 20I0).

O glossário do ICOM explica que para constituir uma verdadeira coleção, é necessário que o conjunto de objetos seja relativamente coerente e significativo, e também ressalta que é importante não confundir coleção com fundo:

Estos últimos, designan un acervo de documentos de todo tipo 'reunidos automáticamente, creados y/o acumulados y utilizados por una persona física o por una familia en el ejercicio de sus actividades o de sus funciones' (Oficina Canadiense de Archivistas, 1992). En el caso de los fondos, contrariamente a una colección, no hay selección y pocas veces la intención de constituir un conjunto coherente (DESVALLÉES; MAIRESSE, 2010).

O ICOM entende que a diferença precisa ser esclarecida, pois as atividades dos arquivos e dos museus se complementam, e é preciso que cada um atue de acordo com seus princípios e normativas, sob pena de não executarem um trabalho eficiente de recuperação da informação.

Para o Dicionário Terminologia Arquivística, coleção "é a reunião artificial de documentos que, não mantendo relação orgânica entre si, apresentam alguma característica em comum" (CAMARGO; BELLOTTO, I 996). O termo "artificial” empregado pelo Dicionário faz o contraponto com o termo "orgânico”, característica típica dos documentos de arquivos.

Para a Sociedade dos Arquivistas Americanos (Society of American Archivists - SAA), coleção é "um grupo de material com alguma característica que os une"; mas também pode ser "o acervo de um depósito"”, já que em língua inglesa é comum o uso do termo "collections" ou "holdings", para o conjunto de documentos de um arquivo.

Para os arquivos, um fundo significa um conjunto de documentos de uma mesma proveniência, que mantêm relação orgânica entre si, já que um documento é mais bem compreendido dentro de seu contexto. $O$ desmembramento de documentos de seu contexto original também pode ser um problema para a descrição e contextualização.

Os museus trabalham com coleções. $O$ que vimos até agora é que os documentos de arquivo não são colecionados, eles são produzidos pela instituição e existe legislação respaldando as atividades. Mas os museus colecionam documentos que, muitas vezes, foram retirados de seu con-

3 O glossário da SAA, na versão em inglês, está disponível em Collection ([2006?]). 
texto por diversas razões, e foram vendidos ou doados a museus, arquivos e bibliotecas. Assim, eles acabam sendo considerados como peças isoladas, recebendo tratamento individualizado (SILVA, 2008, p. 65-66).

Os arquivistas de museus devem estar atentos para os documentos adquiridos, examinando seu contexto de produção para identificar se é fruto de um fundo ou de uma coleção.

\section{Considerações finais}

Os museus são instituições vivas onde muitas atividades são planejadas e executadas anualmente. Também estão constantemente produzindo novos programas e atividades. Por consequências, os arquivos de museus devem acompanhar essa dinâmica no seu planejamento.

O programa de gestão de documentos deve ter flexibilidade para abranger novas atividades e programas, de tal forma que não fique nem engessado, nem ultrapassado. As atividades típicas de museus, como exposições e atividades educacionais deverão estar contempladas no programa de gestão de documentos do museu, de tal forma que os registros sejam recolhidos ao arquivo. $A$ decisão sobre quais documentos deverão ser encaminhados ao arquivo e quais poderão ser eliminados deverá ser conjunta com a equipe de museólogos, após a definição de critérios para a avaliação.

Os arquivistas e museólogos devem trabalhar em parceria para o planejamento das atividades e a definição dos limites de atuação de cada um. Além disso, também devem definir e criar procedimentos para o tratamento técnico dos acervos, bem como os espaços de guarda e as responsabilidades. Esta parceria proporcionará um melhor desempenho no processamento e na preservação do acervo sob a guarda do museu.

A reflexão que se pretendeu desenvolver é fruto de uma realidade cada vez mais emergente nos museus brasileiros, da criação de arquivos nas instituições museológicas, visando ao tratamento dos registros documentais sob a guarda do museu. Há o reconhecimento crescente de que os documentos com características arquivísticas devem ser tratados como tal, aproveitando-se da experiência de ambos os profissionais, arquivistas e museólogos, para que a informação possa ser tratada e recuperada de forma mais rápida e eficiente. $E$ a parceria entre o conhecimento do arquivista com o do museólogo parece ser o caminho mais efetivo para a eficiência.

\section{Referências}

BEVILACQUA, Gabriel Moore. Arquivos em museus: apontamentos a partir da experiência do Centro de Documentação e Memória da Pinacoteca do Estado de São Paulo. In: SEMINÁRIO INTERNACIONAL ARQUIVOS DE MUSEUS E PESQUISA, I., São Paulo, 2010 . Anais... São Paulo: MAC/USP, 20 I0. p. I55- 166.

BRASIL. Lei II.904, de I 4 jan. 2009. Diário Oficial [da] República Federativa do Brasil, Poder Executivo, Brasília, DF, I5 jan. 2009. Seção I, p. I. Disponível em: <http://www.planalto.gov.br/ccivil_03/_Ato2007-20 I0/2009/Lei/LI I 904.htm>. Acesso em 06 mar. 2013.

BRASIL. Lei 8. 159, de 8 de janeiro de 199I. Diário Oficial [da] República Federativa do Brasil, Poder Executivo, Brasília, DF, 09 jan. I 99I. Seção I, p. 455. Disponível em: <http://www.conarq.arquivonacional.gov.br/cgi/cgilua.exe/sys/start. 
htm?from_info_index=I | \&infoid= I00\&sid=52>.Acesso em 06 mar. 2013.

CAMARGO, Ana Maria de Almeida. Arquivos de museus. In: SEMINÁRIO INTERNACIONAL ARQUIVOS DE MUSEUS E PESQUISA, I., São Paulo, 2010. Anais... São Paulo: MAC/USP, 20 I0. p. 22-27.

CAMARGO, Ana Maria de Almeida; BELLOTTO, Heloísa Liberalli (Org.). Dicionário de terminologia arquivística. São Paulo: Núcleo Regional de São Paulo/ Associação dos Arquivistas Brasileiros, Secretaria de Estado da Cultura, 1996.

COLLECTION. In: PEARCE-MOSES, Richard.A glossary of archival and records terminology. [S.I.]:Society of American Archivists, [2006?]. Disponível em: <http:// www2.archivists.org/glossary/terms/c/collection>. Acesso em: I 3 jan. 2013.

DEISS, William. Museum archives. Chicago: Society of American Archivists, 1984. Disponível em: <http://www.archivists.org/catalog/museum-archives.pdf > . Acesso em: I 3 jan. 2013.

DESVALLÉES, André; MAIRESSE, François (Coord.). Conceptos claves de museología. [S.I.]: Armand Colin, 2010. Disponível em: <http://icom.museum/fileadmin/user_upload/pdf/Key_Concepts_of_Museology/Museologie_Espagnol_ BD.pdf>.Acesso em: 05 jan. 2013.

FLECKER, John. Archives and museums. The Midwestern archivist, v. I5, n. 2, p. 67-75, 1990.

IBRAM. Definição de museu. Disponível em: <http://www.museus.gov.br/museu/>.Acesso em: 06 mar. 2013.

INTERNATIONAL COUNCIL OF MUSEUM - ICOM. Código de ética. 2006. Disponível em: <http://archives.icom.museum/codes/Lusofono2009.pdf>. Acesso em: I 3 jan. 2013.

MAGALHÃES, Ana Gonçalves. Arquivos de museus de arte e pesquisa: o Grupo de Trabalho Arquivos de Museus e pesquisa. In: SEMINÁRIO DE SERVIÇOS DE INFORMAÇÃO EM MUSEUS. São Paulo, 20I I.Anais... São Paulo: Pinacoteca do Estado, 20I I. p. II5-I 25.

MORRIS, Sammie L. Starting from scratch: how to create a museum archives. Museline, Texas: Association of Museum, 2003. Disponível em: <http://docs.lib. purdue.edu/lib_research/45/>.Acesso em: 05 nov. 2012.

MUSEU DE ATRONOMIA E CIÊNCIAS AFINS. Política de aquisição e descarte de acervos. Disponível em: <www.mast.br/>.Acesso em: 4 fev. 2013.

PRZYBYLA, Ann Marie. The Museum archives movement. In: SOCIETY OF AMERICAN ARCHIVISTS. Museum archives: an introduction. Chicago: Society of American Archivists, 2004. Museum archives section. p. 3-8.

ROBERTS, Rebecca. Understanding museum archives. [200-?]. Disponível em: <www.gslis.utexas.edu/ vmuseum/roberts.pdf>. Acesso em: 05 nov. 2012.

SILVA, Maria Celina Soares de Mello e.Arquivos históricos de museus: o arquivo de história da ciência do MAST. In: MUSEU DE ASTRONOMIA E CIÊNCIAS AFINS. Documentação em museus. Rio de Janeiro: MAST, 2008. p. 59-66. (Coleção Mast-colloquia, v. 10). Disponível em: <http://www.mast.br/livros/mast colloquia_10.pdf>.Acesso em: 05 nov. 2012.

SILVA, Maria Celina Soares de Mello e. Objetos tridimensionais em arquivos pessoais de cientistas.Arquivo \& Administração, v. I0, n. I, p. 3 I -48, jan./jun. 201 I . SILVA, Maria Celina Soares de Mello e. Scientific instruments in personal archives: acquisition policy and technical treatment. In: SIMPOSIUM OF THE SCIEN- 
TIFIC INSTRUMENT COMMISSION, 3I., Rio de Janeiro 20I2. Anais... Rio de Janeiro: Scientific Instrument Commission, 2012. Poster.

SOCIETY OF AMERICAN ARCHIVISTS. Museum archives guidelines. Disponível em: <www2.archivists.org/standards/museum-archives-guidelines >. Acesso em: 6 jun. 2012.

WYTHE, Deborah (Org.). Museum archives: an introduction. 2. ed. Chicago: Society of American Archivists, 2004. Museum Archives Section.

Artigo recebido em fevereiro de 2013. Aprovado em abril de 2013 